\title{
Interactive comment on "Interaction of Dust Aerosols with Land/Sea Breezes over the Eastern Coast of the Red Sea from LIDAR Data and High-resolution WRF-Chem Simulations" by Sagar P. Parajuli et al.
}

\section{Sagar P. Parajuli et al.}

psagar@utexas.edu

Received and published: 3 September 2020

Thank you very much for providing valuable comments in our manuscript. We find them very helpful, but we want to clarify the queries raised in the review to incorporate the suggestions in the revised manuscript. We agree to structure our manuscript better. The other two reviewers also suggested this. Regarding the link between dust and breezes, we do not consider breezes as a primary generator of dust and a transport system. We agree that the relationships between different aspects of the phenomenon are not evident because the results are scattered in different sections. 
Regarding the topographic effect, we extensively discuss them in Section 3.4 (Figure 14 ), in which the escarpment topography is displayed and discussed along with its impact on dust concentration. Please have a look at this section. The topography indeed has an effect on winds, which we have mentioned in the paper. We understand your concern about looking into more details on surface wind speed, which causes dust emission, and the effect of topography on wind speed. However, our paper's focus is on the vertical profile of aerosols, so we do not go into too much detail on this effect, which can be found in other previous studies (e.g., Davis et al., 2019), as mentioned in our paper.

We also agree to revise the title of the manuscript, as suggested. We will show the diurnal temperature variations at the shore to illustrate the temperature contrast between land and sea, which drives the breeze circulation. We will also revise our text regarding possible mechanisms of dust transport from deserts to our site. There is no simple relationship between temperature and aerosol vertical profile, so the temperature's vertical profile will not really help in our interpretation. We agree that the breezes are formed around the coastal region only, and it is not appropriate to describe them as a control for the whole domain. We will also separate the discussion and conclusion section, which was also suggested by the other two reviewers. We will incorporate all other suggestions into our revisions. We thank you again for your careful review of our manuscript.

Interactive comment on Atmos. Chem. Phys. Discuss., https://doi.org/10.5194/acp-2020-444, 2020. 